\title{
Osteopontin Expression of Circulating T Cells and Plasma Osteopontin Levels are Increased in Relation to Severity of Heart Failure
}

\author{
Hirofumi Soejima, MD*,†; Atsushi Irie, PhD**; Takashi Fukunaga, MD*; Yoko Oe, MD*; \\ Sunao Kojima, MD*; Koichi Kaikita, MD*; Hiroaki Kawano, MD*; \\ Seigo Sugiyama, MD*; Michihiro Yoshimura, MD*; Hideki Kishikawa, MD; \\ Yasuharu Nishimura, MD**; Hisao Ogawa, MD*
}

\begin{abstract}
Background $\mathrm{T}$ cells in peripheral blood reflect the systemic inflammatory response in patients with heart failure (HF). In a rat model of HF, osteopontin is dramatically increased in the left ventricular myocardium, so the association between osteopontin and HF was examined in the present study.

Methods and Results Peripheral blood was collected from 93 patients with heart disease and 38 controls. Left ventricular ejection fraction (LVEF) was calculated using a modified Simpson's rule. The 93 patients were classified into 3 classes according to the New York Heart Association (NYHA) functional classification. Osteopontinexpressing $\mathrm{CD}^{+} \mathrm{T}$ cells were quantified by flow cytometry. Plasma osteopontin levels $(\mathrm{ng} / \mathrm{ml}$ ) and the frequencies of osteopontin-expressing CD4+ $\mathrm{T}$ cells $(\%)$ were higher in patients with HF than in controls $(800 \pm 554$, $575 \pm 229, \mathrm{p}=0.016$ and $27.3 \pm 12.2,16.7 \pm 10.0, \mathrm{p}<0.001)$. Furthermore, the plasma osteopontin levels and the frequencies of osteopontin-expressing $\mathrm{CD}^{+} \mathrm{T}$ cells increased in proportion to the severity of the NYHA functional class. The frequencies of osteopontin-expressing $\mathrm{CD}^{+} \mathrm{T}$ cells were significantly correlated with LVEF $(\mathrm{r}=-0.336, \mathrm{p}=0.0048)$ and $\log$ plasma brain natriuretic peptide levels $(\mathrm{r}=0.305, \mathrm{p}=0.0025)$.

Conclusions Osteopontin expression of circulating CD4 $4^{+} \mathrm{T}$ cells and plasma osteopontin levels reflect the severity of HF. Osteopontin could be a new target in the assessment of HF. (Circ J 2007; 71: 1879-1884)
\end{abstract}

Key Words: Heart failure; Inflammation; Leukocytes

$\mathbf{O}$ steopontin is an adhesion molecule that was first identified in bone tissue, and it has been demonstrated that cardiomyocytes are an important source of osteopontin in left ventricular (LV) hypertrophy in both humans and rodents? Interestingly, Singh et al showed that osteopontin is dramatically increased in the LV myocardium of a heart failure (HF) model in rats, after transition from LV hypertrophy to HF? Furthermore, in a genetic animal model of dilated cardiomyopathy, inflammatory cells express osteopontin, indicating a potential role for osteopontin during inflammatory processes in the heart. The plasma level of osteopontin was reported to be correlated with echocardiographic findings in the population of the Framingham Heart Study 5 and it has been reported that plasma osteopontin levels are elevated in patients with not only unstable angina but also acute myocardial infarction 6,7 Plasma osteopontin levels change time-dependently and the changes are correlated with LV volume and function in patients with acute myocardial infarction? Osteopontin has been reported to be released from the heart into the coronary circulation in proportion to LV systolic function and

(Received June 10, 2007; revised manuscript received August 1, 2007; accepted August 7, 2007)

Departments of *Cardiovascular Medicine, **Immunogenetics, Graduate School of Medical Sciences and ${ }^{\dagger}$ Health Care Center, Kumamoto University, Kumamoto, Japan

Mailing address: Hirofumi Soejima, MD, Department of Cardiovascular Medicine, Graduate School of Medical Sciences, Kumamoto University, 1-1-1 Honjo, Kumamoto 860-8556, Japan. E-mail: yuuki @ gpo.kumamoto-u.ac.jp volumes in patients with a previous anterior wall myocardial infarction? Thus, osteopontin is associated with HF in both humans and animal models.

Osteopontin is abundantly produced in the early stage of $\mathrm{T}$-cell and macrophage activation and is expressed by $\mathrm{T}$ cells and macrophages? Functional studies have shown that osteopontin supports T-cell and macrophage chemotaxis and can costimulate T-cell proliferation $!^{10-12}$ Yndestad et al have shown that the systemic inflammatory response in patients with HF, as assessed by enhanced expression of inflammatory cytokines in peripheral blood mononuclear cells, reflects T-cell and not monocyte activation ${ }^{13}$ Satoh et al have reported that the subpopulation of cytokineexpressing $\mathrm{CD}^{+}{ }^{+} \mathrm{T}$ cell is larger in patients with symptomatic HF than in those with asymptomatic subjects! ${ }^{4}$ Thus, expression of osteopontin and T-cell activation in the heart play an important role in HF. In the present study, we investigated whether the plasma osteopontin level or osteopontinexpressing T cells was a clinically useful marker for HF.

\section{Methods}

Study Population

The study population consisted of 93 consecutive patients with heart disease (65 men, 28 women; mean age $68 \pm 10$ years) between January 2004 and July 2006. The diagnosis of heart disease was based on the patient's clinical history, physical examination, electrocardiogram (ECG), chest X-ray, echocardiogram, left ventriculogram, and coronary angiogram. Patients in New York Heart Association 
Table 1 Characteristics of the 2 Study Groups

\begin{tabular}{|c|c|c|c|}
\hline & Heart failure $(n=93)$ & Control $(n=38)$ & $p$ value \\
\hline \multicolumn{4}{|l|}{ Age (years) } \\
\hline Mean & $68 \pm 10$ & $65 \pm 13$ & 0.132 \\
\hline Range & $22-86$ & $38-83$ & \\
\hline$M / F$ & $55 / 38$ & $28 / 10$ & 0.171 \\
\hline Hypertension & 43 & 23 & 0.237 \\
\hline Smoking & 19 & 13 & 0.149 \\
\hline Diabetes mellitus & 28 & 10 & 0.628 \\
\hline Body mass index $\left(\mathrm{kg} / \mathrm{m}^{2}\right)$ & $23.7 \pm 4.3$ & $23.4 \pm 5.0$ & 0.740 \\
\hline Total cholesterol & $170 \pm 34$ & $189 \pm 34$ & 0.005 \\
\hline HDL-cholesterol & $49 \pm 15$ & $54 \pm 15$ & 0.205 \\
\hline Triglyceride $(\mathrm{mg} / \mathrm{dl})$ & $99(57-159)$ & $117(72-182)$ & 0.124 \\
\hline Etiology ischemic/nonischemic & $35 / 58$ & & \\
\hline Creatinine $(\mathrm{mg} / \mathrm{dl})$ & $1.09 \pm 0.53$ & $0.84 \pm 0.21$ & 0.006 \\
\hline NYHA functional class I/II/III-IV & $30 / 31 / 32$ & & \\
\hline$C$-reactive protein $(\mathrm{mg} / \mathrm{dl})$ & $0.64 \pm 1.26$ & $0.20 \pm 0.31$ & 0.061 \\
\hline Plasma osteopontin $(\mathrm{ng} / \mathrm{ml})$ & $800 \pm 544$ & $575 \pm 289$ & 0.016 \\
\hline Frequency of osteopontin-expressing-CD4 $4^{+} T$ cells (\%) & $27.3 \pm 12.2$ & $16.7 \pm 10.0$ & $<0.0001$ \\
\hline \multicolumn{4}{|l|}{ No. of coronary arteries narrowed $>75 \%$} \\
\hline 0 & 30 & 38 & \\
\hline 1 & 8 & 0 & \\
\hline 2 & 15 & 0 & \\
\hline 3 & 15 & 0 & \\
\hline \multicolumn{4}{|l|}{ Medication on admission } \\
\hline$\beta$-blockers & 25 & 3 & \\
\hline$A C E I$ & 42 & 4 & \\
\hline$A R B$ & 31 & 8 & \\
\hline Calcium-channel blockers & 38 & 13 & \\
\hline Diuretics & 56 & 3 & \\
\hline Statins & 33 & 8 & \\
\hline
\end{tabular}

Data are expressed as mean $\pm S D$, median (10-90th percentile range) or $n$.

HDL, high-density lipoprotein; NYHA, New York Heart Association; ACEI, angiotensin-converting enzyme inhibitor; ARB, angiotensin II type 1 receptor blocker.

(NYHA) functional class I had cardiac disease that did not limit physical activity, such that ordinary physical activity did not cause undue fatigue, palpitation, dyspnea, or anginal pain. The remaining patients were symptomatic for HF. Patients in NYHA functional class III/IV had significant clinical findings (eg, edema, S3, pulmonary congestion). The cause of heart disease was idiopathic dilated cardiomyopathy in 27 patients, hypertrophic cardiomyopathy in 6 , old myocardial infarction in 35 , hypertensive heart disease in 8 , valvular heart disease in 15 , and congenital heart disease in 2. Patients with malignant disease, lung disease, renal failure, collagen disease, liver dysfunction, and other inflammatory diseases were excluded. The NYHA functional classification was evaluated at the time of admission. LV ejection fraction (LVEF) was also measured by Simpson's rule, using echocardiography.

We also included 38 controls without heart disease (28 men, 10 women, mean age $65 \pm 13$ years) who were agematched with the patients. All of the controls underwent diagnostic cardiac catheterization because they had a history of chest pain with multiple risk factors or an ECG abnormality. However, their coronary angiograms revealed no evidence of coronary stenosis or coronary spasm after intracoronary injection of acetylcholine. Written informed consent was given by all subjects before the study. The study was in agreement with the guidelines approved by the institutional ethics committee.

\section{Blood Samples}

Blood samples were obtained from all patients while they were recumbent, using a 21-gauge needle for clean puncture of an antecubital vein. The first $5 \mathrm{ml}$ of blood was used for biochemical assessment, including high-sensitivity Creactive protein (hs-CRP) and brain natriuretic peptide (BNP). Subsequently, $3 \mathrm{ml}$ was collected sequentially into evacuated tubes containing $0.3 \mathrm{ml}$ of EDTA for cytometric analysis of osteopontin expression and plasma osteopontin levels.

\section{Echocardiography}

Two-dimensional and Doppler echocardiographies were performed by the same experienced sonographer using a Vingmed Vivid FiVe System (GE Vingmed, Milwaukee, WI, USA) using a $2.5-\mathrm{MHz}$ phased-array transducer. The images were recorded on videotape and analyzed offline. LV diastolic and systolic dimensions were measured from standard M-mode measurements as recommended by the American Society of Echocardiography ${ }^{15}$ Biplane end-diastolic and end-systolic volumes and LVEF were calculated using a modified Simpson's rule and computer-assisted planimetry! ${ }^{16}$

\section{Flow Cytometric Analysis for Cytokine Expression (Osteopontin)}

A 1.5-ml blood sample containing EDTA was immediately mixed with $1.5 \mathrm{ml}$ of medium [10\% FCS-supplemented RPMI1640 with $40 \mathrm{mg} / \mathrm{ml}$ Brefeldin A (Sigma, St Louis, MO, USA)] and then incubated for $24 \mathrm{~h}$ at $37^{\circ} \mathrm{C}$ and $5 \%$ $\mathrm{CO} 2$. After washing with ice-cold PBS, cells were recovered by centrifugation and adjusted to $5 \times 10^{5}$ white blood cells per test. The fixation and permiabilization of cells were both performed using IntraPrep ${ }^{\mathrm{TM}}$ reagent (Beckman Coulter, High Wycombe, UK). The cells were successively stained with anti-human osteopontin monoclonal antibody (Immuno- 
Table 2 NYHA Functional Classes and Hemodynamic Variables

\begin{tabular}{|c|c|c|c|c|}
\hline & Control $(n=38)$ & Class I $(n=30)$ & Class II $(n=31)$ & Class III/IV $(n=32)$ \\
\hline Heart rate (beats/min) & $72 \pm 16$ & $71 \pm 14$ & $77 \pm 18$ & $82 \pm 16$ \\
\hline Blood pressure (mmHg) & $133 \pm 16 / 78 \pm 15$ & $128 \pm 21 / 75 \pm 11$ & $113 \pm 27 * / 65 \pm 13 *,+$ & $123 \pm 33 / 80 \pm 19$ \\
\hline $\operatorname{LVEF}(\%)$ & $64.4 \pm 11.3$ & $49.7 \pm 15.6^{*}$ & $39.9 \pm 18.3 * *$ & $39.4 \pm 15.8 * *$ \\
\hline$B N P(p g / m l)$ & $21(6-103)$ & $140(29-437) * *, \mathbb{I}$ & $423(34 \pm 1,032) * *, \dagger$ & $655(104-1,747) * *$ \\
\hline Creatinine $(\mathrm{mg} / \mathrm{dl})$ & $0.84 \pm 0.21$ & $1.03 \pm 0.34$ & $1.07 \pm 0.41$ & $1.16 \pm 0.74 *$ \\
\hline \multicolumn{5}{|l|}{ Medication on admission } \\
\hline$\beta$-blockers & 3 & 5 & 10 & 10 \\
\hline$A C E I$ & 4 & 7 & 19 & 16 \\
\hline$A R B$ & 8 & 10 & 15 & 6 \\
\hline Calcium-channel blockers & 13 & 11 & 11 & 16 \\
\hline Diuretics & 3 & 13 & 21 & 22 \\
\hline Statins & 8 & 12 & 15 & 6 \\
\hline
\end{tabular}

Data are expressed as mean $\pm S D$ or median (10-90th percentile range).

$L V E F$, left ventricular ejection fraction; BNP, brain natriuretic peptide. Other abbreviations see in Table 1.

${ }^{*} p<0.05,{ }^{*} p<0.0001$, vs Control; ${ }^{\dagger} p<0.05$, ${ }^{\ddagger} p<0.01,{ }^{\text {II }} p<0.0001$ vs Class III/IV.

Biological Laboratories, Fujioka, Japan), PE-labeled antimouse IGg antibody (BD Pharmingen, San Diego, CA, USA), and FITC-labeled anti-human CD4 antibody (BD Pharmingen). The flow cytometric analysis was performed to evaluate cytokine expression using a FACScan ${ }^{\mathrm{TM}}$ instrument (Becton Dickinson, San Jose, CA, USA). Nonspecific staining with the isotype-matched control monoclonal antibody was $<1 \%$.

\section{Plasma Osteopontin Measurement}

The remaining 1.5-ml blood sample containing EDTA was used for analyzing plasma osteopontin levels by ELISA (Immuno-Biological Laboratories, Fujioka, Japan). Plasma samples were immediately stored at $-80^{\circ} \mathrm{C}$ until analysis. The ELISA kit was recently developed, based on the method reported by Kon et $\mathrm{al}^{17}$ and it measures the total concentration of phosphorylated and nonphosphorylated forms of osteopontin in plasma. The intra- and inter-assay coefficients of variation for this kit were $6.8 \%$ and $13.3 \%$, respectively. The normal (mean $\pm \mathrm{SD}$ ) value for plasma osteopontin level measured in our laboratory $(n=20)$ was $556 \pm 173 \mathrm{ng} / \mathrm{ml}$.

\section{Statistical Analysis}

All data are given as mean $\pm \mathrm{SD}$, but the data for triglycerides and BNP are shown as a median value $\left(10-90^{\text {th }}\right.$ percentile range). The comparisons of continuous data among the 4 patient groups were performed with 1-way ANOVA followed by Scheffé's test. The comparisons of continuous data between 2 patient groups were performed with unpaired t-test. The comparisons of osteopontin, CRP and BNP data among the 4 patient groups were performed using the Kruskal-Wallis test followed by the Dunnett procedure. The comparisons of osteopontin, CRP and BNP data between 2 patient groups were performed using Mann-Whitney's U-test. Frequency data among the 4 or 2 patient groups were compared using the $\mathrm{X}^{2}$ test. Linear regression analysis was used to determine the correlation between 2 variables. Pvalues $<0.05$ were considered to be statistically significant.

\section{Results}

\section{Patient Characteristics}

The 93 patients with heart disease were classified into 3 NYHA classes: 30 patients were in NYHA class I, 31 in class II, and 32 in class III/IV.

The clinical characteristics of the study subjects are shown in Table 1. There were no significant differences in gender, age, and coronary risk factors between the 2 study subject groups.

Heart rate was the highest in patients in NYHA class III/ IV (Table 2) and blood pressure was lowest in patients with NYHA class II. LVEF was significantly lower in patients in NYHA classes I, II and III/IV than in the controls (class I vs controls: $p=0.0164$; class II vs controls: $p<0.0001$; class III/ IV vs controls: $\mathrm{p}<0.0001)$. LVEF tended to be reduced in patients in NYHA classes II and III/IV compared with patients in NYHA class I. There was no significant difference in LVEF between patients in NYHA class II and those in NYHA class III/IV. The BNP levels were the highest in patients in NYHA class III/IV and were significantly higher in patients in NYHA classes I and II than in controls $(\mathrm{p}<$ $0.001)$. Moreover, each group had significant differences in plasma BNP levels.

\section{Assessment of Osteopontin Levels}

The plasma osteopontin levels $(\mathrm{ng} / \mathrm{ml})$ were significantly increased in patients with HF compared with controls $(800 \pm 554$ vs $575 \pm 229, \mathrm{p}=0.016)$ (Table 1$)$. The plasma osteopontin levels $(\mathrm{ng} / \mathrm{ml})$ were the highest in patients in NYHA class III/IV (Fig 1). The plasma osteopontin levels $(\mathrm{ng} / \mathrm{ml})$ in patients in NYHA classes II $(787 \pm 499, \mathrm{p}=0.034)$ and III/IV (997 $\pm 707, \mathrm{p}=0.0008)$ were higher than those in controls (604 \pm 253$)$ (Fig 1). There was no significant deference in the plasma osteopontin levels of patients in NYHA I $(604 \pm 253)$ and the controls. The plasma osteopontin levels in patients in NYHA classes II $(\mathrm{p}=0.049)$ and III/IV $(p=0.002)$ were higher than those in patients in NYHA class I (Fig 1).

\section{Frequency of Osteopontin-Expressing T Cells}

We examined the frequency of osteopontin-expressing CD4+ $\mathrm{T}$ cells among the $\mathrm{T}$ cells by flow cytometry. The frequency of osteopontin-expressing $\mathrm{CD}^{+}{ }^{+} \mathrm{T}$ cells $(\%)$ were significantly increased in patients with HF compared with controls $(27.3 \pm 12.2$ vs $16.7 \pm 10.0, \mathrm{p}<0.0001)$ (Table 1$)$. The frequency of osteopontin-expressing $\mathrm{CD} 4+\mathrm{T}$ cells $(\%)$ was the highest in patients in NYHA class III/IV (Fig2). The frequencies of osteopontin-expressing CD4 ${ }^{+} \mathrm{T}$ cells $(\%)$ in patients in NYHA class I $(25.7 \pm 11.7, \mathrm{p}=0.003)$, NYHA class II $(26.3 \pm 13.0, \mathrm{p}=0.008)$ and NYHA class III/IV (29.9 \pm $12.2, \mathrm{p}<0.0001)$ were higher than in the controls $(16.7 \pm$ 10.0) (Fig 2). The frequencies of osteopontin-expressing $\mathrm{CD}^{+}{ }^{+} \mathrm{T}$ cells in patients in NYHA classes II and III/IV 

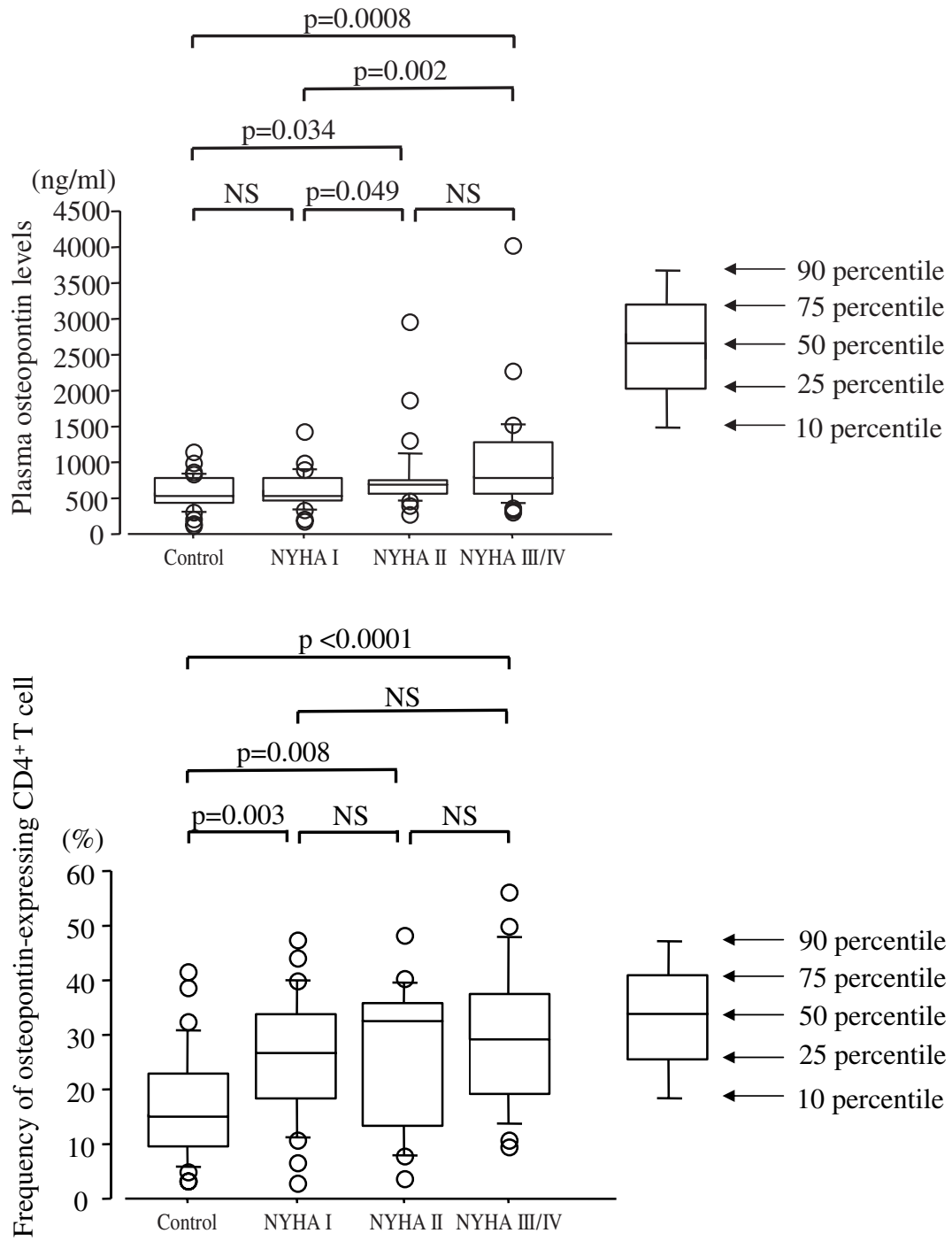

Fig 1. Comparison of plasma osteopontin levels among the patients in New York Heart Association (NYHA) functional classes I, II, and III/IV and in the controls. were higher than in patients in NYHA class I (Fig 2), but not significantly.

\section{Relationship Among the 4 Markers}

The log plasma osteopontin levels did not correlate with the frequency of osteopontin-expressing CD $4^{+} \mathrm{T}$ cells, but were significantly and positively correlated with the log plasma BNP levels ( $r=0.335, p=0.0002$, Fig 3 Upper left); they were not correlated with LVEF $(r=0.155, p=0.1551)$. On the other hand, the frequency of osteopontin-expressing CD4+ $\mathrm{T}$ cells was negatively correlated with LVEF $(\mathrm{r}=-0.336$, $\mathrm{p}=0.0048$, Fig 3 Lower left) and positively correlated with log plasma BNP levels $(r=0.305, p=0.0025$, Fig 3 Lower right).

\section{Assessment of hs-CRP Levels}

The serum hs-CRP levels $(\mathrm{mg} / \mathrm{dl})$ tended to be increased in patients with HF compared with controls $(0.64 \pm 1.26$ vs $0.20 \pm 0.31, \mathrm{p}=0.061)$ (Table 1$)$. The hs-CRP levels were the highest in patients in NYHA class III/IV (Fig 4). The hs-CRP levels $(\mathrm{mg} / \mathrm{dl})$ in patients in III/IV $(0.99 \pm 1.8)$ were higher than those in controls $(0.20 \pm 0.31, \mathrm{p}=0.002)$ and in patients in NYHA class I $(0.45 \pm 0.92, \mathrm{p}=0.012)$ (Fig 4$)$. There was no significant deference in the hs-CRP levels $(\mathrm{mg} / \mathrm{dl})$ among the patients in NYHA classes I and II $(0.41 \pm 0.56)$ and controls. The log hs-CRP levels were positively correlated with the frequencies of osteopontin-expressing $\mathrm{CD}^{+}{ }^{+}$ T cells $(r=0.302, p=0.0028)$, but not significantly correlated with log plasma osteopontin levels, or log plasma BNP levels, or LVEF.

\section{Discussion}

To the best of our knowledge, this study is the first clinical analysis of plasma osteopontin levels and osteopontin expression by T cell in patients with HF. The present study provides clinical evidence that plasma osteopontin levels and the frequency of osteopontin-expressing $\mathrm{CD}^{+}{ }^{+} \mathrm{T}$ cells change in association with NYHA functional class. Thus, the plasma osteopontin level or osteopontin-expressing $\mathrm{T}$ cells may be a clinically useful marker for HF. Devaux et al ${ }^{18}$ qualitatively evaluated and counted cell adhesion molecules of tissue obtained at transplantation from patients with either myocarditis, chronic ischemic heart disease or dilated cardiomyopathy, and from controls. They demonstrated upregulation of cell adhesion molecules in human chronic HF and that it was independent of the cause of HF. Therefore, in the present study we used osteopontin, which is an adhesion molecule, as a marker for HF.

We and others have shown that BNP is predominantly 


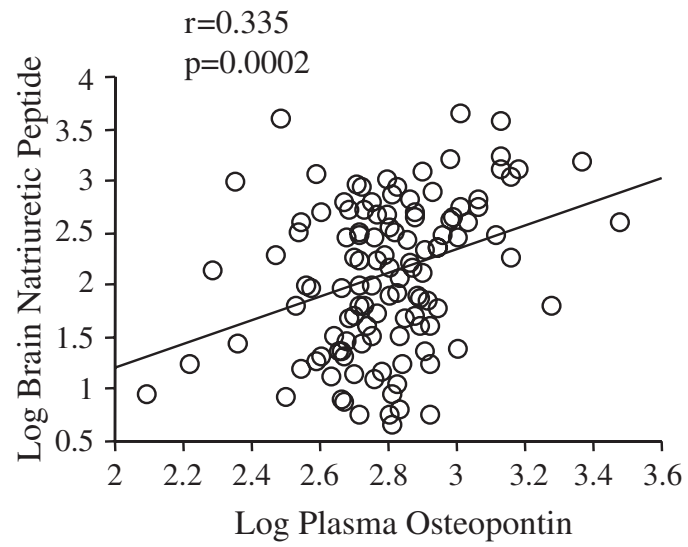

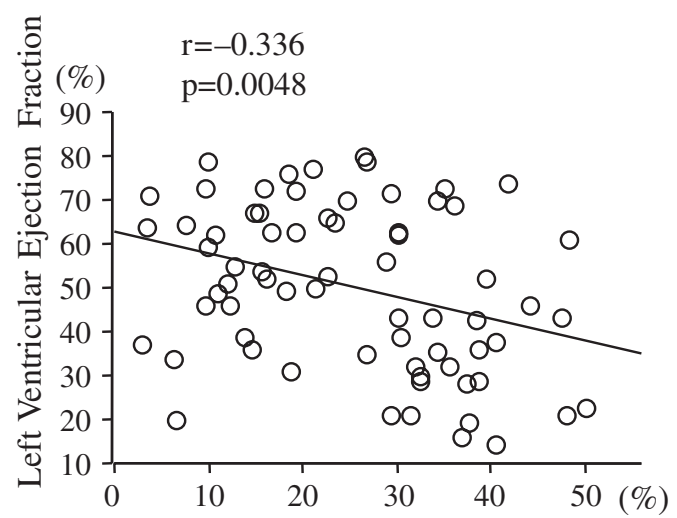

Frequency of osteopontin-expressing $\mathrm{CD}^{+}{ }^{+} \mathrm{T}$ cell

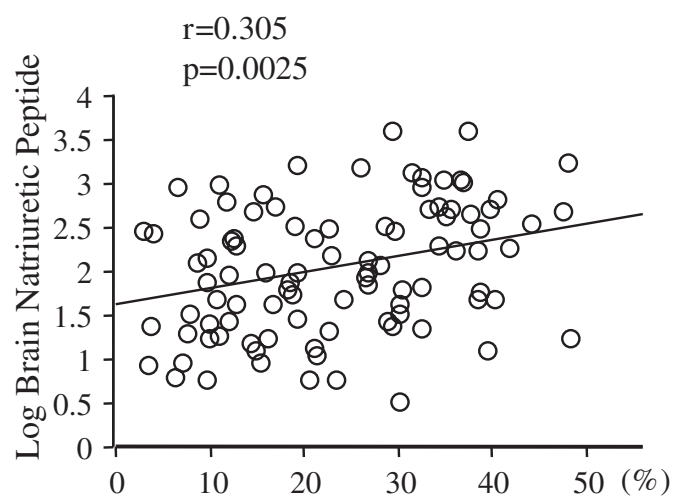

Frequency of osteopontin-expressing $\mathrm{CD}^{+}{ }^{+} \mathrm{T}$ cell

Fig 3. (Upper left) Correlation between the log plasma osteopontin level and the log plasma BNP level. (Lower left) Correlation between the left ventricular ejection fraction and the frequency of osteopontin-expressing CD4+ $\mathrm{T}$ cells. (Lower right) Correlation between the log brain natriuretic peptide and the frequency of osteopontin-expressing $\mathrm{CD}^{+} \mathrm{T}$ cells.

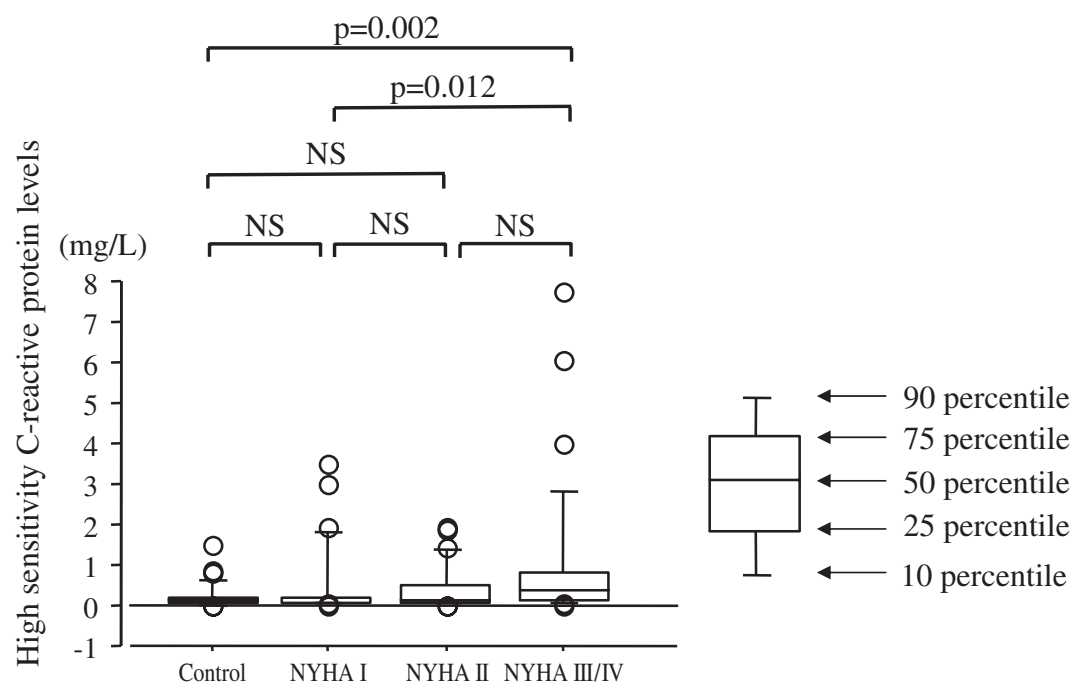

Fig 4. Comparison of high-sensitivity C-reactive protein levels among the patients in New York Heart Association (NYHA) functional classes I, II, and III/IV and in the controls. secreted and released from the ventricles in proportion to the severity of LV dysfunction in patients with $\mathrm{HF}$, and there is increasing evidence that BNP is a sensitive marker of the severity of HF ${ }^{19-22}$ In the present study, plasma BNP levels significantly increased in proportion to the severity of the NYHA functional class. Both the log plasma osteopontin level and the frequency of osteopontin-expressing CD4+ $\mathrm{T}$ cells were significantly correlated with the log plasma BNP levels. These results suggest that factors and/or mech- anisms involved in HF are associated with increased osteopontin expression.

Recently, Stawowy et al examined the expression of osteopontin in myocardial biopsies obtained from patients with HF caused by dilated cardiomyopathy and compared it with that of patients with a normal LVEF 23 The osteopontin expression of cardiomyocytes was higher in the former group. Their data are compatible with our finding that both the plasma osteopontin level and the frequency of osteopon- 
tin-expressing $\mathrm{CD}^{+} \mathrm{T}$ cells are increased in patients with HF compared with controls. In addition, statistical analysis revealed a significant correlation of increased osteopontin expression in cardiac myocytes with impaired LVEF in Stanomwy et al's data. In the present study, the frequency of osteopontin-expressing-CD4+ $\mathrm{T}$ cells, but not the plasma osteopontin level, was significantly correlated with LVEF. Damas et al ${ }^{24}$ demonstrated that $\mathrm{T}$ cell in patients with HF showed enhanced expression of MIP-la and GROa and that their corresponding receptors were expressed in cardiomyocytes, suggesting a potential for inflammatory interaction involving T-cell mediated mechanisms within the failing myocardium. A role for $\mathrm{T}$ cells in the promotion of myocardial failure is also supported by studies in animal models demonstrating $\mathrm{T}$ cell activation during cardiac injury and importantly, these $\mathrm{T}$ cells have been found to retain a memory response against cardiomyocytes, recognizing and killing these cells.5 These facts may explain the reason why markers of failing myocardium, such as LVEF, are more strongly associated with the frequency of osteopontinexpressing $\mathrm{CD}^{+}{ }^{+} \mathrm{T}$ cells than with the plasma osteopontin level.

It has been reported that osteopontin is released from the heart into the coronary circulation in patients with myocardial infarction ${ }^{8}$ and that cardiomyocytes are an important source of osteopontin in LV hypertrophy? We found CD4+ $\mathrm{T}$ cells to be a source of plasma osteopontin in HF. However, further study is needed to reveal what mechanisms in $\mathrm{HF}$ lead to osteopontin production from the myocardium or from circulating $\mathrm{T}$ cells.

In conclusion, we have demonstrated for the first time that both the osteopontin expression of circulating $\mathrm{CD} 4+\mathrm{T}$ cells and the plasma osteopontin level increase in proportion to the severity of the NYHA functional class in patients with HF. Analyzing peripheral T-cell activation could represent a new target in the assessment or treatment of HF.

\section{Acknowledgments}

This study was supported in part by a grant-in-aid for Scientific Research (No. C17590751) from the Ministry of Education, Culture, Sports, Science and Technology in Japan, a grant from Japan Arteriosclerosis Prevention Fund and a Smoking Research Foundation grant for Biomedical Research, Tokyo, Japan.

\section{References}

1. Oldberg A, Franzen A, Heinegard D. Cloning and sequence analysis of rat bone sialoprotein (osteopontin) cDNA reveals an Arg-Gly-Asp cell-binding sequence. Proc Natl Acad Sci USA 1986; 83: 88198823.

2. Graf K, Do YS, Ashizawa N, Meehan WP, Giachelli CM, Marboe $\mathrm{CC}$, et al. Myocardial osteopontin expression is associated with left ventricular hypertrophy. Circulation 1997; 96: 3063-3071.

3. Singh K, Sirokman G, Communal C, Robinson KG, Conrad CH, Brooks WW, et al. Myocardial osteopontin expression coincides with the development of heart failure. Hypertension 1999; 33: 663-670.

4. Williams EB, Halpert L, Wickline S, Davison G, Parks W, Rottman $\mathrm{J}$. Osteopontin expression is increased in the heritable cardiomyopathy of Syrian hamsters. Circulation 1995; 92: 705-709.

5. Arnlöv J, Evans JC, Benjamin EJ, Larson MG, Levy D, Sutherland $\mathrm{P}$, et al. Clinical and echocardiographic correlates of plasma osteopontin in the community: The Framingham Heart Study. Heart 2006; 92: $1514-1515$.

6. Soejima H, Irie A, Fukunaga T, Sugamura K, Kojima S, Sakamoto T, et al. Elevated plasma osteopontin levels were associated with osteopontin expression of $\mathrm{CD} 4^{+} \mathrm{T}$ cells in patients with unstable angina. Circ J 2006; 70: 851-856.

7. Suezawa C, Kusachi S, Murakami T, Toeda K, Hirohata S, Nakamura
$\mathrm{K}$, et al. Time-dependent changes in plasma osteopontin levels in patients with anterior-wall acute myocardial infarction after successful reperfusion: Correlation with left-ventricular volume and function. J Lab Clin Med 2005; 145: 33-40.

8. Tamura A, Shingai M, Aso N, Hazuku T, Nasu M. Osteopontin is released from the heart into the coronary circulation in patients with a previous anterior wall myocardial infarction. Circ J 2003; 67: $742-$ 744.

9. O'Regan AW, Chupp GL, Lowly JA, Goetschkes M, Mulligan N, Berman JS. Osteopontin is associated with T cells in sarcoid granulomas and has T cell adhesive and cytokine-like properties in vitro. $J$ Immunol 1999; 162: 1024-1031.

10. Yamamoto S, Nasu K, Ishida T, Setoguchi M, Higuchi Y, Hijiya N, et al. Effect of recombinant osteopontinon adhesion and migration of 388D1 cells. Ann NY Acad Sci 1995; 760: 378-380.

11. Singh RP, Patarca R, Schwartz J, Cantor H. Definition of the specific interaction between the early $\mathrm{T}$ lymphocyte activation 1 (Eta-1) protein and the murine macrophages in vitro and its effect upon macrophages in vivo. J Exp Med 1990; 171: 1931-1942.

12. Giachelli CM, Lombardi D, Johnson RJ, Murry CE, Almedia M. Evidence for a role of osteopontin in macrophage infiltration in response to pathological stimuli in vivo. Am J Pathol 1998; 152: 353-358.

13. Yndestad A, Holm AM, Muller F, Simonsen S, Froland SS, Gullestad $\mathrm{L}$, et al. Enhanced expression of inflammatory cytokines and activation markers in T-cells from patients with chronic heart failure. Cardiovasc Res 2003; 60: 141-146.

14. Satoh S, Oyama JI, Suematsu N, Kadokami T, Shimoyama N, Okutsu $\mathrm{M}$, et al. Increased productivity of tumor necrosis factor-alpha in helper $\mathrm{T}$ cells in patients with systolic heart failure. Int $J$ Cardiol 2005; 11: 405-412.

15. Sahn DJ, Demaria A, Kisslo J, Weyman A. Recommendations regarding quantitation in M-mode echocardiography: Results of a survey of echocardiographic measurements. Circulation 1978; 58: $1072-1083$.

16. Schiller NB, Shah PM, Crawford M, Demaria A, Devereux R, Feigenbaum $\mathrm{H}$, et al. Recommendations for quantitation of the left ventricle by two-dimensional echocardiography: American society of echocardiography committee on standards, subcommittee on quantitation of two-dimensional echocardiograms. J Am Soc Echocardiogr 1989; 2: 358-367.

17. Kon S, Maeda M, Segawa T, Hagiwara Y, Horikoshi Y, Chikuma S, et al. Antibodies to different peptides in osteopontin reveal complexities in the various secreted forms. J Cell Biochem 2000; 77: $487-$ 498.

18. Devaux B, Scholz D, Hirche A, Klovekorn WP, Schaper J. Upregulation of cell adhesion molecules and the presence of low grade inflammation in human chronic heart failure. Eur Heart J 1997; 18: 470-479.

19. Yoshimura M, Yasue H, Okumura K, Ogawa H, Jougasaki M, Mukoyama M, et al. Different secretion patterns of atrial natriuretic peptide and brain natriuretic peptide in patients with congestive heart failure. Circulation 1993; 87: 464-469.

20. Yasue H, Yoshimura M, Sumida H, Kikuta K, Kugiyama K, Jougasaki M, et al. Localization and mechanism of secretion of Btype natriuretic peptide in comparison with those of A-type natriuretic peptide in normal subjects and patients with heart failure. Circulation 1994; 90: 195-203.

21. Grantham JA, Burnett JC Jr. BNP: Increasing importance in the pathophysiology and diagnosis of congestive heart failure. Circulation 1997; 96: $388-390$.

22. Cowie MR, Struthers AD, Wood DA, Coats AJ, Thompson SG, Poole-Wilson PA, et al. Value of natriuretic peptides in assessment of patients with possible new heart failure in primary care. Lancet 1997; 350: 1349-1353.

23. Stawowy P, Blaschke F, Pfautsch P, Goetze S, Lippek F, WollertWulf $\mathrm{B}$, et al. Increased myocardial expression of osteopontin in patients with advanced heart failure. Eur J Heart Fail 2002; 4: 139146.

24. Damas JK, Eiken HG, Oie E, Bjerkeli V, Yndestad A, Ueland T, et al. Myocardial expression of CC- and CXC-chemokines and their receptors in human end-stage heart failure. Cardiovasc Res 2000; 47: $778-787$.

25. Varda-Bloom N, Leor J, Ohad DG, Hasin Y, Amar M, Fixler R, et al. Cytotoxic T lymphocytes are activated following myocardial infarction and can recognize and kill healthy myocytes in vitro. J Mol Cell Cardiol 2000; 32: 2141-2149. 